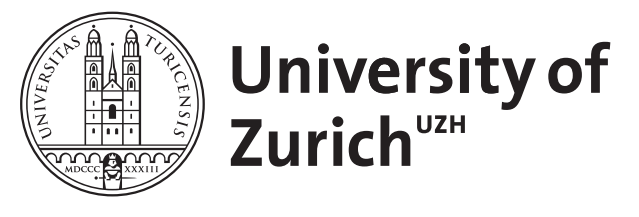

\title{
The dual role of human dignity in bioethics
}

\author{
Andorno, Roberto
}

\begin{abstract}
This paper argues that some of the misunderstandings surrounding the meaning and function of the concept of human dignity in bioethics arise from a lack of distinction between two different roles that this notion plays: one as an overarching policy principle, and the other as a moral standard of patient care. While the former is a very general concept which fulfils a foundational and a guiding role of the normative framework governing biomedical issues, the latter reflects a much more concrete and context-specific understanding of the patient as a "person". The importance of dignity as a policy principle will be described by appealing to the distinction between principles and rules as developed by some legal philosophers. The value of dignity as a standard of patient care will be illustrated with the help of concrete examples and by drawing on the taxonomies of dignity proposed by Jonathan Mann and other scholars. The overall scope of the article is to highlight this double and complementary role of human dignity in bioethics.
\end{abstract}

DOI: https://doi.org/10.1007/s11019-011-9373-5

Posted at the Zurich Open Repository and Archive, University of Zurich

ZORA URL: https://doi.org/10.5167/uzh-68948

Journal Article

Accepted Version

Originally published at:

Andorno, Roberto (2013). The dual role of human dignity in bioethics. Medicine Health Care and Philosophy, 16(4):967-973.

DOI: https://doi.org/10.1007/s11019-011-9373-5 


\title{
The dual role of human dignity in bioethics
}

Roberto Andorno

\begin{abstract}
This paper argues that many of the misunderstandings surrounding the meaning and function of the concept of human dignity in bioethics arise from a lack of distinction between two different roles that this notion plays: one as an overarching policy principle, and the other as a moral standard of patient care. While the former is a very general concept which fulfils a foundational and a guiding role of the normative framework governing biomedical issues, the latter reflects a much more concrete and context-specific understanding of the patient as a "person". The importance of dignity as a policy principle will be described by appealing to the distinction between principles and rules as developed by some legal philosophers. The value of dignity as a standard of patient care will be illustrated with the help of concrete examples and by drawing on the taxonomies of dignity proposed by Jonathan Mann and other scholars. The overall scope of the article is to highlight this double and complementary role of human dignity in bioethics.
\end{abstract}

\section{Introduction}

During the last decade, the notion of human dignity has been at the centre of a heated debate concerning the role (if any) that this concept is called to play in bioethics, and in particular in the policy documents on biomedical issues. On the one hand, this notion is at the foundation of the international human rights system which emerged in the aftermath of the Second World War, and more recently, of the international documents relating to bioethics adopted by intergovernmental bodies such as the UN, UNESCO, and the Council of Europe. On the other hand, the invocation of dignity in bioethical discourse has attracted serious criticisms from a number of philosophers who see it as a purely rhetorical or political notion. In an already famous article in the BMJ, Ruth Macklin has called dignity a "useless concept" since, in her view, it means no more than "respect for autonomy" and can therefore be simply "eliminated without any loss of content" (Macklin 2003).

It is interesting to note that Macklin's argument was rejected with vehemence by several doctors and nurses who wrote rapid responses to the BMJ between December 2003 and January 2004. They claim that dismissing dignity risks disregarding the ultimate rationale for respecting each patient as a unique and irreplaceable person. Also, they argue that dignity cannot simply be equated with autonomy because, as one of them writes, "one may treat a patient with respect in the ways the author refers to, like honoring their autonomy, and still not treat them with the dignity they deserve. I have seen many times an informed consent filled out by patients treated with little dignity" (Taylor 2003). Moreover, dignity cannot be a synonym of autonomy for the simple reason that also people with greatly limited autonomy (such as those suffering mental retardation) or those who totally lack moral autonomy (like newborns) are widely regarded as having dignity (Allison 2003; Ford 2003).

Commenting on this debate, Alex Capron has rightly pointed out that the controversy is somehow misleading because both Macklin and her critics are talking of different things: the former are concerned with dignity in the particular sense of treating patients in a dignified fashion, while Macklin criticizes the use of the term in a general manner, as is conveyed by international policy instruments relating to bioethics (Capron 2003). However, in my opinion, it would be wrong to conclude from this that there is a "bad" use of dignity (as a general principle) and a "good" one (as a concrete vision of patient's care). The aim of this article is precisely to argue that there is no real conflict between these two different approaches to human dignity. Rather, they can be regarded as two complementary expressions of the same widely shared view that all human beings possess an equal and inherent worth. 


\section{Dignity as an overarching policy principle}

\section{Human dignity in international human rights law}

The entire international human rights system that emerged after 1945, as well as the legal systems of all democratic countries are based on the assumption that people do really have inherent dignity and are therefore entitled to basic rights. In modern political thought, the state's raison d'être is precisely to promote and secure respect for dignity and rights. This presupposes that legal norms do not create human rights from nothing; that people's rights are not the capricious invention of lawmakers, who could legitimately revoke them in a change of humour. Rather, individual states, as well as the international community, are morally obliged to recognize that all people have basic rights (i.e. that they have equally valid claims to basic goods) because these latter derive from the dignity which is inherent in every human being. This is precisely what is meant by the Universal Declaration of Human Rights (UDHR) when it provides that "everyone has the right to recognition everywhere as a person before the law" (Article 6).

Certainly, the practical efficacy of promoting human rights is significantly aided by their legal recognition by states. But the ultimate validity of basic rights is characteristically thought of as not conditional upon such recognition (Nickel 1987). The explicit use of the verb "to recognize" in the UDHR, which denotes the formal acknowledgment of something that already exists, is very illuminating in this respect.

It is noteworthy in this regard that legal systems do not present the notion of human dignity as a merely metaphysical hypothesis or as an arbitrary legal fiction, but as the indispensable basis for the fair functioning of human society. All human beings qua humans are regarded as really deserving to be treated with unconditional respect and entitled with basic rights regardless of age, sex, physical or mental abilities, ethnic origin, religion, political ideas, socio-economic status, or any other particular condition or circumstance. This is the core idea behind the concept of human dignity.

At this point it should be noted that, contrary to what is sometimes maintained in bioethical circles, especially in the Anglo-American context, the idea of intrinsic human dignity does not rely on a "speciesist" claim, i.e. on the merely biological fact of belonging to the species Homo sapiens. Rather, it is based on the indisputable fact that human beings are entities capable, as a kind, of understanding, self-understanding, loving, self-determining by judging and choosing, expressing themselves by means of arts, etc. These extraordinary abilities that characterize human beings as a kind and qualitatively distinguish them from all other known living beings (even if those capacities are not currently present in all human individuals, or not in all to the same degree) make of every human being something absolutely unique, precious and irreplaceable. Certainly, if there were other entities in the universe besides human beings having, as a kind, the above mentioned capacities, they would also have intrinsic dignity (Sulmasy 2007).

Another recurrent objection to the use of human dignity concerns the circumstance that this concept is never defined neither by law. But the truth is that this lack of definition does not by itself prove that dignity is an empty concept or a purely rhetorical notion. As a matter of fact, defining dignity in clear-cut terms would be as difficult as defining 'freedom,' 'justice', 'solidarity', or whatever other key social value (which by the way are never defined by law). It is not because the idea of human dignity is too poor, but because it is too rich that it cannot be encapsulated into a straightforward definition with which everybody agrees. In reality, its core meaning is quite clear and simple and embodies a very basic requirement of justice towards every individual. This requirement presupposes that "each person possesses an inviolability founded on justice that even the welfare of society as a whole cannot override" (Rawls 1973, p. 3).

Even in the absence of a definition, international law offers a helpful guidance for a better understanding of the concept of dignity when it provides: first, that dignity is "inherent... to all members of the human family" (UDHR, Preamble); second, that all human beings are "free and equal in dignity and rights" (UDHR, Article 1); third, that "these rights derive from the inherent dignity of the human person" (International Covenant on Civil and Political Rights and International Covenant on Social, Economic and Cultural Rights, Preambles). This latter statement is particularly crucial: if basic rights are grounded on the inherent worth of every human being, and not on a merely contingent decision of lawmakers or of the international community, then they cannot be taken away by any authority.

If the whole international human rights law system is grounded on the idea of human dignity, the much more explicit and massive recourse to this notion in the recent instruments relating to bioethics is really impressive. This leads some to characterize human dignity as the "shaping principle" of international bioethics (Lenoir and Mathieu 2004, p. 16).

Certainly, the principle of respect for human dignity is by its very nature vague and general. Normally it does not provide per se practical guidance in defining responses to particular issues. But, as we will see below, the same happens with all general principles. This is why, in order to render 
human dignity more easily operational, the emerging instruments in this field combine the appeal to human dignity as an overarching principle with the recourse to a broad range of human rights that are relevant to health issues (Andorno 2009).

A good example of this combined appeal to human dignity and human rights in this area is provided by the three UNESCO declarations relating to bioethics: the Universal Declaration on the Human Genome and Human Rights (1997), the International Declaration on Human Genetic Data (2003), and the Universal Declaration on Bioethics and Human Rights (2005). The latter one has the merit of showing that human dignity plays not one, but several, different roles, which are not exclusive from each other: a) It embodies the central aim of the Declaration (Art. 2.c); it is the first principle governing the whole field of biomedicine (Art. 3); c) It is the main argument against every form of discrimination, including for instance, genetic discrimination (Art. 11); d) It is the framework within which cultural diversity is to be respected (Art. 12); e) It offers the interpretive key of all the provisions of the Declaration (Art. 28).

Similarly to the UNESCO documents, the European Convention on Human Rights and Biomedicine of 1997 ("Oviedo Convention") and its additional Protocols give a pivotal role to human dignity. According to Article 1 of the Convention, which refers to the purpose and object of the document, provides that "Parties to this Convention shall protect the dignity and identity of all human beings and guarantee everyone, without discrimination, respect for their integrity and other rights and fundamental freedoms with regard to the application of biology and medicine." Hence, the purpose of the Convention is presented in two stages: first, the protection of dignity and identity of human beings; second, the safeguard of people's integrity and other rights. This means that a distinction is made between dignity and rights.

Also Article 2 of the Biomedicine Convention is noteworthy in this respect because it offers a direct corollary of the idea of human dignity which is particularly relevant in the field of bioethics: the primacy of the human being over science and society. The 'primacy principle', which originates in the first version of the famous Declaration of Helsinki of 1964 (Principle I.5), is like an echo of the Nuremberg trials that condemned the Nazi physicians. Far from being a "vacuous figure of speech" (Helgesson and Eriksson 2008), it seeks to capture a very fundamental idea: that "the person does not have to reach any functional standard to be valuable as a person or to be treated with full respect" (Parker 2010). In other words, the life and physical integrity of every individual (of every patient and of every research participant) has intrinsic worth, and should therefore not be treated as mere instruments for the benefit of science or society.

Another important point that needs to be made is that human dignity is usually characterized in negative terms, for instance, by saying that it embodies the idea that people must "never be treated in a way that denies the distinct importance of their own lives" (Dworkin 1994, p. 236), or that "there are some things that should not be done to anybody, anywhere" (Midgley 1999, p. 160). It is not by chance that, while most human rights are couched in positive terms in international law ("Everyone has the right to..."), those that aim to protect people against the most serious violations of human dignity are formulated in negative terms, in the form of prohibitions: "No one shall be held in slavery or servitude"; "no one shall be subjected to torture or to cruel, inhuman or degrading treatment or punishment" (Articles 4 and 5 of the UDHR, respectively). Precisely because these rights derive very directly from human dignity they are thought of as absolute, in the sense that they are not subject to any exceptions.

The meaning of dignity can indeed be better grasped by considering what is contrary to it rather than what is in conformity with it. Evil is easier to identify than goodness. It is when we are confronted to the worst things that can be done to a human being that we better understand, by contrast, what "dignity" means. Even the Kantian categorical imperative according to which no one is to be treated as a mere means to another's end can be regarded as example of this via negativa. Therefore it can be claimed that the first and primary task of the principle of human dignity is to set a minimal threshold of respect for every human being, i.e. to clearly indicate what practices are absolutely incompatible with a civilized society. Only after having established that minimum, the legal system can seek to promote people's well-being in positive terms.

This shows that the principle of respect for human dignity operates on two different levels: the first and most important, as a negative requirement, when it absolutely forbids certain practices and therefore does not allow any balance with other goods or principles. But human dignity can also function as a positive requirement, notably, the improvement of people's quality of life (for instance, through better schools and hospitals, a more efficient transportation system, etc.). Such measures, which are ultimately grounded on the idea of human dignity, are of course desirable, but not absolutely imperative (at least not at any cost), and might therefore be weighed against other social goods (for instance, the available financial resources of a society).

Another brief remark that has to be made here is that the principle of human dignity is in recent years used not only to promote respect for the intrinsic worthiness of every individual, but also of 
humankind as a whole. This derivative (or secondary) understanding of the classic notion of human dignity takes place in the debate on some technologies that are regarded as a threat to the identity and integrity of the human species such as human reproductive cloning and germ-line interventions. On the one hand, the criticisms of the use of human dignity with this broader meaning are understandable, since it is much more abstract than the traditional one, and can be misused, especially when it is employed as a discussion-stopper and without any additional explanation. On the other hand, we must acknowledge that we do not have at hand any other term to refer to the value of humankind as such other than 'human dignity'. It must be noted that resorting to human rights is insufficient to cope with the new biotechnological challenges since human rights only belong to existing individuals, not to humanity as a whole.

\section{Human dignity as a principle}

Is the appeal to human dignity made by international policy documents superfluous? Does the notion of dignity add something to the much more concrete norms specifying human rights? What is the relationship between dignity and rights? These crucial questions lead us to resort to a conceptual distinction, which is common in legal philosophy: the one between rules and principles.

Although there is a long tradition in law to refer to principles, the distinction between rules and principles has become especially important in the last decades as a matter of philosophical inquiry. Ronald Dworkin was probably the first legal philosopher to systematically develop the differences between these two categories of norms (Dworkin 1977, p. 22-28). According to him, both sets of standards point to particular decisions about legal obligation, but they differ in the character of the direction they give. Rules are applicable in an all-or-nothing fashion. They require a complete fulfilment: they can only be either fulfilled or not. If the facts a rule stipulates are given, then either the rule is valid, in which case the answer it supplies must be accepted, or it is not, in which case it contributes nothing to the decision. For instance, if a norm prohibits driving faster than $50 \mathrm{~km}$ per hour, then the rule can only be either fulfilled or not; it is not a matter of degree. There could be however exceptions, for instance, in the case of a police car pursuing the robbers of a bank, or of an ambulance bringing a dying person to hospital.

But this is not the way principles work. Principles have a dimension of weight (or importance). When principles intersect, one has to take into account the relative weight of each one in order to resolve the conflict. Neither of the colliding principles loses its validity, but the losing principle is considered to have less significance in the particular case. In other words, while conflicts between rules are solved either by subsuming one of the rules under the other as an exception, or by declaring one of them invalid, the collision between principles is to be solved in a process of weighing.

The crucial point here is that principles alone do not completely determine the content of a particular decision. They just establish that something must be carried out to the greatest possible degree in relation to the factual and legal possibilities. Principles are "optimization commands" (Optimierungsgebote), which can be carried out to different degrees depending on the circumstances (Alexy 1994, p. 71-77).

Interestingly, many, if not most legal norms contain principles, not rules. Thus their provisions can be applied to different degrees, and will only become a rule after having been weighed against other competing principles. Even human rights, as they are formulated in legal documents, are principles, not rules; they do not provide per se a clear-cut solution to concrete dilemmas; they have to be balanced with other principles (such as competing rights, the common good of society, etc.) in order to help providing a fair solution to a particular case.

Alexy explicitly mentions human dignity as a principle, which only becomes a rule after having been balanced against other principles. Like all principles, also dignity is unable by itself to provide practical guidance in defining responses to particular issues. But this does not mean that it is useless. We should not expect from the idea of human dignity more than it can offer. Anyway, as Alexy points outs, even if dignity has to be weighed against other principles, it is very likely to have priority over any of them. Dignity is in this regard a kind of "super-principle" which not only provides the foundation of all legal and social institutions, but also shows a general direction towards which a civilized society should tend.

In any case, it seems that this process of weighing only applies to human dignity when it deploys a positive role. On the contrary, as mentioned above, when dignity accomplishes its primary task as a negative requirement and absolutely forbids specific practices (torture, inhuman and degrading treatment or punishments, etc.), it cannot be weighed against any other principle. In such cases, which are rather exceptional, dignity operates more like a rule than like a principle.

Another question that needs to be briefly addressed here concerns the relation between human dignity and human rights. In particular: why do we need the notion of dignity if we already have that (much more concrete) of human rights? Is dignity not a mere collective term to refer to rights? The fact 
is that international law clearly distinguishes between dignity and rights: rights derive from human dignity; human dignity is the foundation of human rights; human dignity is not a kind of super-right, but rather the ultimate source of all rights. The idea of human dignity intends to respond to the question "why do human beings have rights?". And the answer is that they are entitled to rights precisely because they possess intrinsic worth.

\section{Dignity as a moral standard of patient care}

\section{Dignity and vulnerability}

While dignity as an overarching principle fulfils a foundational and guiding role of the whole normative framework governing biomedical issues, dignity as a standard for patient care embodies a much more concrete and context-specific vision of the patient as a "person". Both approaches, far from being in conflict, are just two different sides of the same coin. They are complementary. The general approach (dignity as a policy principle) is the objective component of dignity: it refers to the inherent value that society recognizes in each of us; it is about how others see each of us. The concrete approach (dignity as a standard for patient care) relates to the subjective component of dignity: it is a consequence of the inherent value that I recognize in myself; it is about how I see myself; it results from my awareness of being a 'subject' and not a mere 'object'; it leads me, if I am a patient, to reasonably expect certain attitudes and behaviours from health care professionals.

Why is paying adequate attention to the dignity of each patient crucial in health care? Why is the consideration of how patients perceive themselves to be seen by others (i.e. by health providers) essential for good medical practice? The reason for this is that patients are in a situation of greater vulnerability; they are particularly exposed to see their self-esteem affected as they are deeply dependent on the assistance of others, not only for the improvement of their health condition, but also for meeting their most basic needs. This makes them more sensitive to any behaviour or attitude of health care professionals that might bee seen as a disregard for their intrinsic value as persons. The etymology itself of the word "patient" puts in evidence this relationship with vulnerability. This term comes from the Latin verb "patior," meaning to endure, bear or suffer, and refers to an acquired vulnerability and dependency imposed to patients by their health situation (Chochinov 2002).

This close relationship that exists between dignity and vulnerability is somehow paradoxical: the concept of human dignity has been traditionally associated with the highest rational capacities with which human beings are endowed, with autonomous decision-making capacity, or even with the human power to dominate nature. But the fact is that dignity is more visible in weakness than in power, in vulnerability than in self-sufficiency. Probably the reason for this is that in the most vulnerable individuals (such as newborns, elderly, seriously ill and dying patients, people suffering from mental disabilities, etc.) human dignity is not hidden behind the ornaments of great intellectual or physical abilities, or good health, or beauty. The worthiness of the human person is here exposed in its nakedness; it is shown in its pure form. If this explanation is right, one may conclude that, either one is able to recognize the inherent dignity of human beings in the most vulnerable individuals, or will never really understand what dignity means. Physicians and nurses are well aware of this as they are constantly confronted with the human being in its simple existence, and are required by the very nature of their profession to discover the value of every patient in that particular situation. They intuitively notice the crucial importance of keeping in mind that each patient, no matter what his or her diagnosis, is not a 'case', a 'disease', or a room number, but a person with a unique character.

The patient-health care professional relationship is indeed a paradigmatic occasion for a careful and active defence of patient's dignity. Certainly, this responsibility does not only rely on doctors and nurses but also on family members, friends and fellow patients. Pellegrino describes well this need for a dignity-promotion behaviour when he notes that patients, especially the seriously ill and dying ones, are acutely sensitive to the way others in their presence react to them:

"The visitor's look of shock on entering the patient's room, the poorly disguised pity, the slight turning away of the eyes, the ever shorter visits, the struggle to say something meaningful, the mournful countenance, the recoil from bodily contact -those reactions all sustain the patient's conviction that she or he is no longer a respected, needed or wanted member of their community or society" (Pellegrino 2008, p. 527).

If promotion of patients' dignity has always been a crucial element of the medical profession, it has become especially urgent in the time pressured context of modern health care. In increasingly bureaucratic, impersonal and commercialized hospitals, the risk is high of overlooking that kindness, 
humanity and respect for each individual patient are still (and will always be) core values of the practice of medicine. This is why emphasizing the notion that every human being is uniquely valuable and therefore must be esteemed highly is today more important than ever.

\section{A taxonomy of dignity}

In the last decade a large number of empirical studies have been carried out to better understand what dignity concretely means from the patient's perspective, either in negative other in positive terms. In this regard, the tireless human rights and public health advocate Jonathan Mann has proposed a helpful taxonomy of dignity. He has identified four general ways in which dignity risks being violated, especially in the health care context (Mann 1998):

a) Not being seen. It occurs when patients feel they have been ignored or insufficiently acknowledged by health care professionals. For example, if a physician does not signal awareness of the patient's presence by avoiding shaking hand or making eye contact, patients may feel that their dignity is threatened.

b) Being seen but only as a member of a group. This may happen, for instance, when patients are mainly regarded as "women", or "senile", or "handicapped", or as members of any other general category. This inclusion into a group may certainly have relevance for an appropriate diagnosis and treatment but, if not properly handled, risks hurt the dignity of patients since they may feel that their individual character is denied.

c) Violations of the bodily space. Health care practice often leads patients to disrobe and expose their bodies to expert scrutiny. But, unless impossible (for instance, in unconscious patients) physical examinations must always be made with the explicit patient's permission and with an explanation of what is being done to him or her. For the same reason, doctors must always ask the patient's permission to include students or trainees in the clinical examination.

d) Humiliation. This factor of dignity violation, which is to some extent present in the three previous categories, might for instance happen when patients feel ashamed by the careless way in which they are treated by the hospital personnel, or interrogated about their health insurance, or subtly discriminated on the grounds of their poor social or economic status.

But dignity cannot only be violated. It can (and must) also be positively promoted. Nora Jacobson has identified several ways in which patients feel their dignity is enhanced by health care professionals' behaviour. She mentions, among others: "presence" (keeping others company); "concealment" (covering up embarrassing markers of illness); "independence" (facilitating, as far as possible, patient's self-sufficiency and moral agency); levelling (minimizing asymmetry); "creativity" (allowing patients of making or sharing art); "courtesy" (demonstrating common respect); and "authenticity" (honouring individuality and personhood) (Jacobson 2009).

According to Canadian psychiatrist Harvey Chochinov, the concept of "dignity" provides an overarching framework that is able to guide the physician, patient, and family in defining the objectives and modalities of any medical intervention. He has conducted one of the few empirical studies to specifically examine the understanding of dignity by patients in an advanced stage of cancer and proposed a new model of care for patients nearing death: the "dignity-conserving care" model. This model includes three broad areas of influence of individual perceptions of dignity: illness-related concerns, i.e. those things that directly result from the illness itself; the dignity-conserving repertoire, ie. those aspects of patients' psychological and spiritual landscape that influence their sense of dignity; and the social dignity inventory, i.e. those social issues or relationship dynamics that enhance or detract from a patient's sense of dignity (Chochinov 2002).

More recent studies having focused on the meaning of patient dignity in hospital settings come to similar conclusions: the consideration of patients' dignity is of paramount importance to health care and its maintenance can contribute to the 'emotional comfort' that may assist recovery (Matiti and Trorey 2008; Baillie 2009). A number of key themes that help enhancing patients' dignity are identified: privacy; confidentiality; communication and the need for information; choice, control and involvement in care; respect and decency and forms of address (Matiti and Trorey 2008). The multi-factorial nature of patient dignity is highlighted by the fact that it includes very heterogeneous elements such as feelings (feeling comfortable, in control and valued), physical presentation, and staff behaviour (Baillie 2009). 


\section{CONCLUSION}

The notion of human dignity plays two different and complementary roles in bioethics: one, as an overarching principle that serves as the ultimate foundation and guiding ideal of the legal norms relating to biomedicine; the other, as a standard for concrete health care decisions at the bedside.

Dignity as a general principle has a central place in policy documents relating to biomedical issues. It basically emphasizes the inherent value of every human being. This general appeal to human dignity does not intend to determine alone the content of particular decisions but, more modestly, to show the overall aim of policy documents and, at the same time, to give an ultimate reason for moving towards that direction. This is why the recourse to human dignity is often combined with the appeal to a wide range of health-related rights, which provide a more effective and practical way forward for dealing with bioethical matters.

Dignity as a standard of health care reflects a concrete and context-specific understanding of the patient as a "person". It relates to the interaction between patients and health care professionals in the specific and varied circumstances in which they find themselves. The importance of dignity in this context results from the special vulnerability that accompanies illness or injury; it requires from doctors, nurses, and hospital staff to actively promote the dignity of patients in every encounter, and to avoid all behaviours that can hurt patients' self-esteem.

\section{References}

Alexy, R. 1994. Theorie der Grundrechte. Frankfurt: Suhrkamp.

Andorno, R. 2009. Human Dignity and Human Rights as a Common Ground for a Global Bioethics. Journal of Medicine and Philosophy 34(3): 223-240.

Baillie, L. 2009. Patient dignity in an acute hospital setting: A case study. International Journal of Nursing Studies, 46(1):23-37.

Beauchamp, T. 2010. Universal Principles and Universal Rights, in Human Rights and Biomedicine, ed. A. den Exter, Antwerp: Maklu Press, 49-66.

Capron, A. 2003. Indignities, Respect for Persons, and the Vagueness of Human Dignity (Rapid Response to Ruth Macklin. Dignity is a useless concept. BMJ 2003; 327: 1419-20), BMJ 31 December 2003.

Chochinov, H.M. 2002. Dignity-Conserving Care. A New Model for Palliative Care. Helping the Patient Feel Valued. JAMA 287(17): 2253-2260.

Dworkin, R. 1977. Taking Rights Seriously. Cambridge: Harvard University Press.

Ford, N. 2003. Dignity is Fundamental (Rapid Response to Ruth Macklin. Dignity is a useless concept. BMJ 2003; 327:1419-20), BMJ 24 December 2003.

Helgesson, G. and Eriksson, S. 2008. Against the principle that the individual shall have priority over science, Journal of Medical Ethics 34(1):54-56.

Jacobson, N. 2009. A taxonomy of dignity: a grounded theory study. BMC International Health and Human Rights 9 (3):1-9. Available online at: http://www.biomedcentral.com/1472-698X/9/3

Johnson, P.R. 1998. An Analysis of 'Dignity'. Theoretical Medicine and Bioethics 19(4): 337-352.

Lenoir, N. and Mathieu, B. 2004. Les normes internationales de la bioéthique, Paris: PUF.

Mann, J. 1998. Dignity and Health: The UDHR's Revolutionary First Article. Health and Human Rights 3(2): 30-38.

Macklin, R. 2003. Dignity is a useless concept. BMJ 327: 1419-20.

Matiti, M., Trorey, G. 2008, Patients' expectations of the maintenance of their dignity. Journal of Clinical Nursing, 17, 2709-2717.

Midgley, M. 1999. Towards an ethic of global responsibility. In Human Rights in Global Politics, ed. T. Dunne and N.J. Wheeler, Cambridge: Cambridge University Press.

Nickel, J. 1987. Making Sense of Human Rights: Philosophical Reflections on the Universal

Declaration of Human Rights. Berkeley: University of California Press.

Parker, C. 2010, The moral primacy of the human being. Journal of Medical Ethics 36(9): 563-566.

Pellegrino, E. 2008. The Lived Experience of Human Dignity. In: US President's Council on Bioethics

(ed.), Human Dignity and Bioethics. Washington DC: US Government Printing Office: 513-539.

Rawls, J. 1973. A Theory of Justice. Oxford: Oxford University Press.

Sulmasy, D. 2007. Human Dignity and Human Worth. In Perspectives on Human Dignity: A Conversation, ed. J. Malpas and N. Lickiss, 9-18, Dordrecht: Springer.

Taylor, S. 2003. Reductio ad absurdum (Rapid Response to Ruth Macklin. Dignity is a useless concept. BMJ 2003; 327:1419-20), BMJ 20 December 2003. 